\title{
Inverse relationship between Leydig cell density and metastatic potential of prostatic adenocarcinoma
}

\author{
W. John Wang *, Y. Albert Yeh*, Paul Stout* and \\ Kang Fan ** \\ Department of Pathology, John L. McClellan \\ Memorial VA Hospital and University of Arkansas \\ Medical Sciences Campus Little Rock, AR, USA \\ Received 2 October 1999 \\ Accepted 29 December 1999
}

Purpose: Evaluate the relationship between metastatic potential of prostatic adenocarcinoma (PC) and testicular Leydig cell density.

Materials and methods: Tissue samples from 111 men, age 52-85, with PC and bilateral orchiectomy were evaluated for Leydig cell density. The patients were divided into two groups: Group A were patients with metastasis $(n=36)$ and Group B were patients without metastasis $(n=75)$. Leydig cell density was determined by direct manual microscopic cell count on the tissue sections. The means of cell counts by four pathologists, expressed as cell/ $/ 0.78 \mathrm{~mm}^{2}$ were used for analysis. The normally distributed data were analyzed by two-tail Student's $t$-test. Thirty-eight age-compatible autopsy cases who died of unrelated causes served as normal controls.

Results: The mean of Leydig cell count in group A patients was 14.43 (14.43 \pm 1.19 SE). Mean of Group B was 47.05 $(47.05 \pm 4.05 \mathrm{SE})$ whereas normal controls displayed a mean of 48.66 (48.66 $\pm 2.94 \mathrm{SE})$. Group A was significantly different from control $(p<0.00001)$. Group A and Group B were also significant different $(p<0.001)$ whereas control was not significantly different from Group B $(p>0.75)$.

Conclusions: Patients with metastatic adenocarcinoma of prostate, as a group, have a significantly lower Leydig cell

*Present address: J. John Wang: Department Pathology, University of Mass, Worcester, MA, USA; Y. Albert Yeh: Department of Pathology, Columbia P\&S, New York, NY, USA; Paul Stout: Department of Pathology, St. Vincent Infirmary, Little Rock, AR, USA.

${ }^{* *}$ Correspondences should be addressed to: Dr. Kang Fan, Department of Pathology \& Lab. Medicine (113), John L. McClellan Memorial VA Hospital, 4300 W. 7th Street, Little Rock, AR 72205, USA. Tel.: +1 501257 6435; Fax: +1 501257 6430; E-mail: kfan@life.uams.edu. density than patients without metastasis or patients without PC in compatible age groups. The hormonal relationship between this observation is however unknown. One possible explanation is that PC subpopulation with metastatic potential may require different level of endogenous androgen or are androgen-independent.

Keywords: Prostatic adenocarcinoma, Leydig cells, metastasis, orchiectomy

\section{Introduction}

Development and physiological maintenance of prostate require androgens [1-5]. Clinical and experimental evidence indicates that in some prostate adenocarcinomas (PC), tumor progression requires testosterone or its principal functional metabolite, dihydrotestosterone (DHT) [6-12]. In human, testicular Leydig cells, in response to luteinizing hormone stimulation, are the primary source of endogenous androgens $[13,14]$ while adrenals are the minor producers. Based primarily on these observations, therapeutic orchiectomy and chemical anti-androgen therapy, in addition to prostatectomy, are some of the treatment modalities in the clinical management of PC. A correlative analysis of Leydig cell density with PC metastatic potential however has not been comprehensively studied, although PC was shown to have significantly lower values of $5 \alpha$-reductase and DHT concentrations as compared to benign prostatic hypertrophy [15].

In this report we describe the relationship between Leydig cell density and PC clinical behavior or metastatic potential.

\section{Materials and methods}

The Leydig cell density was determined by direct microscopic morphological enumeration on the orchiectomy specimens from 111 patients with biopsy 
proven PC. The patients were divided into two groups at time of orchiectomy: Group A, PCs with distant metastasis, 36 cases, and Group B, PCs without metastasis, 75 cases. In our institutes, bilateral orchiectomies, in some selected cases, were performed for therapeutic deprivation of endogenous androgen for PC patients, with or without metastasis. Testes from thirty-eight age-compatible (52-85 years old) autopsy cases who died of unrelated causes served as normal controls. Cases with known underlying causes that affected testis were excluded from the control group. Leydig cell density was expressed as cell count $/ 0.78 \mathrm{~mm}^{2}$ (approximately equals to an area viewed under a $200 \times$ resolution, using a microscopy with standard $10 \times$ eyepiece and $20 \times$ objective lens, means of enumeration on five different microscopic fields in one routine paraffin-embedded H\&E stained tissue section of each case were obtained. The means of four pathologists who independently enumerated the Leydig cell density on different sections from the same case were calculated and the data thus obtained were recorded and analyzed by two-tail Student's $t$ test, using a computer program (Sigma Plot, SPSS, Inc., Chicago, IL). The frequency distribution of the data were found approximately normal with continuous variable within the finite range and thus could be empirically analyzed by the distribution of Student's $t$. Inter-observer variation was analyzed similarly.

\section{Results}

The mean of Leydig cell density in Group A patients was 14.43 (14.43 $\pm 1.19 \mathrm{SE})$, Group B patients, 47.05 $(47.05 \pm 4.05 \mathrm{SE})$ and normal controls, 48.66 (48.66 \pm $2.94 \mathrm{SE})$. By two tail Student's $t$-test, assuming equal variances or unequal variances, Group A was significantly different from normal controls $(p<0.001)$, while Group A and Group B were also statistically highly different $(p<0.001)$. The PC without metastasis group (Group B) and normal controls (Group C) were however not significantly different $(p>0.757)$. The inter-observer variation was not significant $(p>$ $0.95)$.

The testes obtained from postmortem examination of patients who died from causes other than prostatic carcinoma could be divided into 4 groups according to age: Group 1: age 52-60, 6 patients, Group 2: age 61-70, 18 patients, Group 3: age 71-80, 10 patients and Group 4: age $81-85,4$ patients. The causes of death of this control group varied from acute myocardial infarct ( 9 cases), atherosclerotic cardiovascular disease with congestive heart failure (5 cases), squamous cell carcinoma of lung (8 cases), adenocarcinoma of colon with metastasis (6 cases), aspiration pneumonia (5 cases), malignant lymphomas (diffuse high grade B cell, 1 case) and cerebrovascular accidents ( 4 cases). These diseases were a fairly typical representation for causes of death in our institutes. Table 1 summarized the number of patients in each age groups studied. Table 2 lists the means of Leydig cell count of each age group in non-PC control cases, PC cases with metastases and PC cases without metastases. The $p$-values of each age-group are significant between PC without metastasis or non-PC controls and PC with metastasis $(p<0.01)$. The $p$-values of Leydig cell density between each age group of non-PC and $\mathrm{PC}$ cases with metastasis are highly significantly $\left(p<0.001\right.$, ranged from $3.0 \times 10^{-11}$ to $\left.1.15 \times 10^{-7}\right)$. The $p$-values between PC cases without metastasis and normal control in each age group are not statistically significant ( $p>0.79)$. The $p$-values between PC cases with metastases and PC cases without metastasis are highly significant $\left(p<0.001\right.$, range from $3 \times 10^{-14}$ to $\left.2.77 \times 10^{-8}\right)$ in each age group.

The intragroup $p$-values are not significant in PCwith metastasis or normal controls. The intragroup $p$ values in PC without metastasis are not significant between age Groups 1, 2 and 3. The $p$-value between age Group 1 and Group 4 in PC without metastasis is however significant $(p=0.05)$ but in view that the number of patients in these two age subgroups are small, a

Table 1

Number of patients in each age group studied

\begin{tabular}{lccc}
\hline Age group & PC with metastasis & PC without metastasis & Controls \\
\hline Group 1 & 2 & 12 & 6 \\
Group 2 & 14 & 25 & 18 \\
Group 3 & 16 & 30 & 10 \\
Group 4 & 4 & 8 & 4 \\
\hline
\end{tabular}

Age groups: Group 1: age 52-60, Group 2: age 61-70, Group 3: age 71-80, Group 4: age 81-85. 


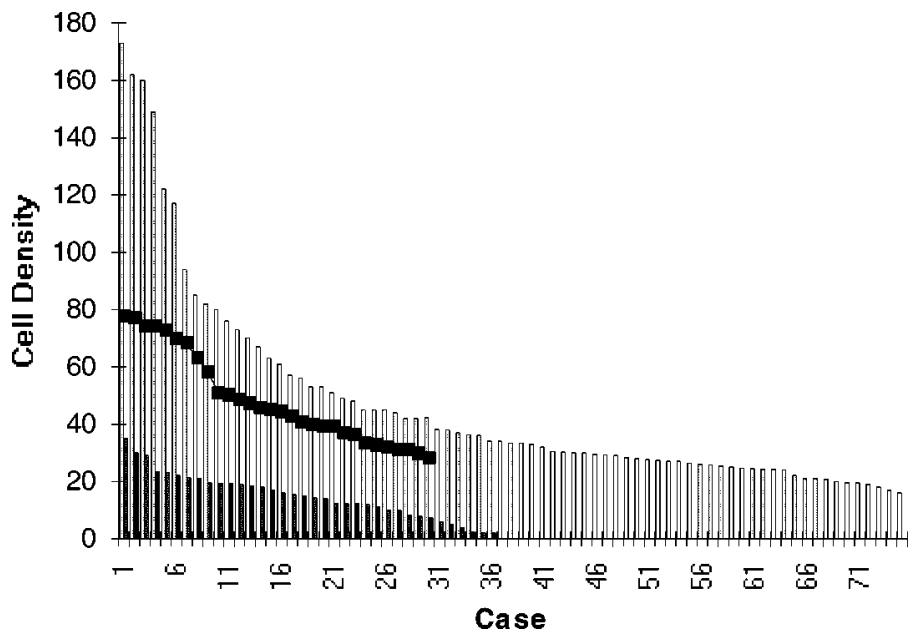

Fig. 1. Testicular Leydig cell density in patients with prostatic adenocarcinoma. Square: Normal age-compatible controls. Clear column: Cases without distant metastases. Solid column: Cases with distant metastases. Cell density expressed as mean cell count/0.78 mm ${ }^{2}$. Data are sorted in descending order according to Leydig cell density. Each column represents one patient.
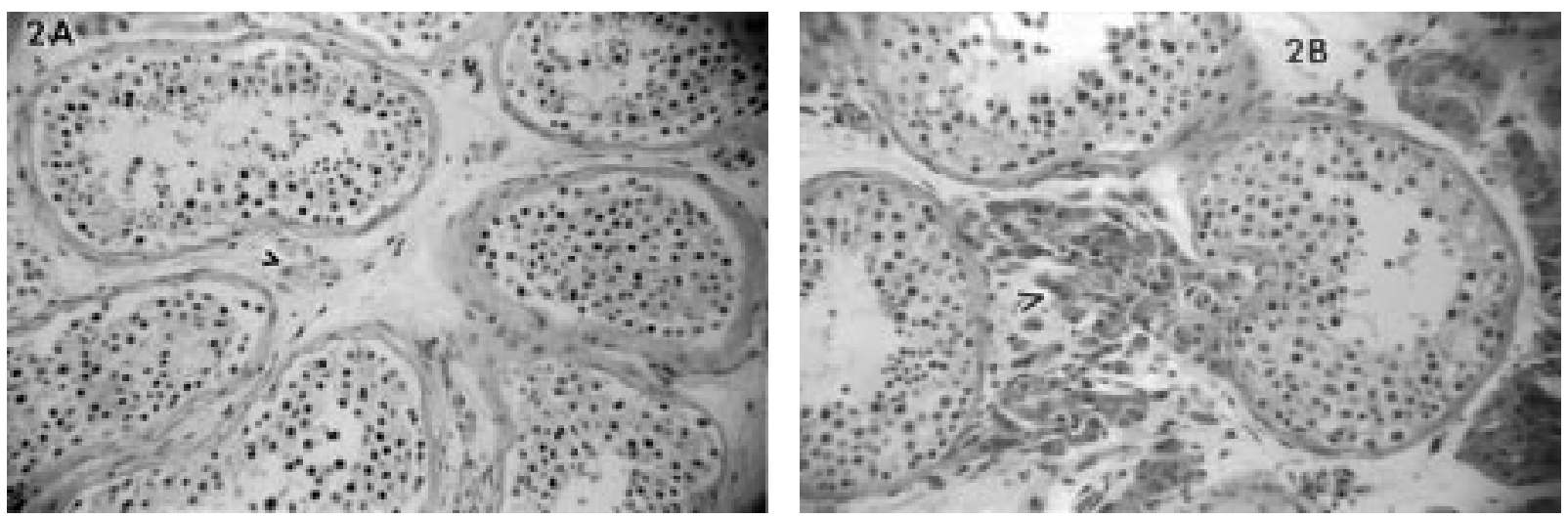

Fig. 2. Representative photomicrographs of testis in a prostatic carcinoma with metastasis (2A) and case without evidence of distant metastasis (2B). Arrows, Leydig cells. $\times 200, \mathrm{H} \& \mathrm{E}$.

larger number of patients is required to draw a statistically satisfactory conclusion.

From the $p$-values, significant difference is noted between control and PC with metastasis in each age group. The $p$-value between control and PC cases without metastasis however reveals no statistical significant difference. It appears that the Leydig cell density displays a slight decline in non-PC controls as patients aged. However, by linear correlative regression analysis (Sigma Plot), Leydig cell density and age distribution within these 38 control patients was $r=-0.6406(\times 1)$, suggesting that a slight negative slope presents but that may not be statistically significant as linear.

From data presented, it appears that PC patients can be best grouped into two major groups as based on the testicular Leydig cell density. Group A, PC patients with low Leydig cell density and high incidence of metastasis, and Group B, PC patients with high or normal range Leydig cell density and low incidence of metastasis. The difference of Leydig cell density observed between these two groups was age independent since no statistically significant age difference was observed between these two groups. Histogram of the distribution of means of Leydig cell count per $0.78 \mathrm{~mm}^{2}$ is presented in Fig. 1. Representative photomicrographs of testes with low (Group A) and high (Group B) Leydig cells are presented as Fig. 2. Number of patients in each age group is tabulated in Table 1. The mean Leydig cell density of each age group is presented in Table 2. 
Table 2

Mean Leydig cell density in each age group of PC cases with or without metastasis and non-PC controls

\begin{tabular}{lccc}
\hline Age group & PC without metastasis & PC with metastasis & Non-PC controls \\
\hline Group 1 & $44.74 \pm 9.91$ & $14.40 \pm 5.2$ & $58.80 \pm 9.4$ \\
Group 2 & $42.05 \pm 8.59$ & $17.41 \pm 2.3$ & $49.11 \pm 3.8$ \\
Group 3 & $37.17 \pm 3.92$ & $14.54 \pm 1.8$ & $44.70 \pm 2.51$ \\
Group 4 & $64.23 \pm 24.62$ & $11.32 \pm 2.5$ & $37.44 \pm 3.11$ \\
\hline
\end{tabular}

Expressed as mean cell count $/ 0.78 \mathrm{~mm}^{2} \pm \mathrm{SE}$ (approximately $200 \times$ microscopic field). The $p$-values among groups and intragroups refer to text results section.

In this study, correlative analysis between Gleason's morphological grade and Leydig cell density was not performed. However, of the 36 cases with distant metastases, 28 cases have a combined score 7 or higher than 7 , and 8 cases have a combined score ranged from 4 to 6 , as evaluated from the tumors at the primary site.

\section{Discussion}

The results were unexpected in view that the majority of prostate adenocarcinoma is known to be androgen dependent. Higher level of in vivo available endogenous androgens is expected to promote PC cell proliferation and enhancing metastatic potential. Since Leydig cells are the major source of endogenous androgens production, individuals with decreased number of morphologically identifiable Leydig cells would suggest reduced available endogenous androgens which was however not quantitatively measured in this study. We however observed that the group of patients with metastatic adenocarcinoma of prostate has a significantly lower Leydig cell density than that of the non-metastatic group or normal control group while no significant differences were found between the non-metastatic group and normal control group. This observation suggests that prostatic carcinoma with metastatic potential may require different level of androgen for growth or is androgen-independent. This possibility is supported by a recently published experimental observation that human prostate tumor growth in athymic mice was inhibited by androgens whereas the cell proliferation was stimulated by finasteride [21].

The number of Leydig cells decreases with age but age is only one of the factors accounting for the attrition of Leydig cells in aging men [16]. In our series, age apparently was not a causative contributory factor for the observed reduced Leydig cell density in patients with metastatic prostatic carcinomas, since the $p$-value between each of the age group of patients with prostatic carcinoma but without metastasis and corresponding control age group was not statistically significant, and the correlation coefficient of Leydig cell number vs. age is only about 0.22 . Previous studies suggested that androgen deprivation induces apoptosis of normal prostatic acinic epithelial cells [17,18] but androgen deprivation therapy could increase tumor grade, and reduce nuclear and nucleolar size [19,20]. It is however, not certain that these biological and morphological alterations would enhance PC metastatic potential.

We present the data here merely as reporting a not previously described observation. In view of such strong correlation between Leydig cell density and PC with or without distant metastasis, a working hypothesis presumably should be postulated. We therefore hypothesized that the mechanism for the inception of prostatic carcinoma and attrition of Leydig cell in patients with prostatic carcinoma are two unrelated events. When both independent events occur, a subpopulation of tumor cells that requires lower level of androgen for growth or is androgen-independent may acquire a selective advantage over other tumor cells that possess no metastatic potential but require higher level of androgen for growth within the prostate gland. Other possible mechanisms including mutation in androgen receptors in the subpopulation with metastatic potential, different level of expression of estrogen receptor beta (ER-beta) [22,23] in the tumor cells and possibly nutritional factors. Nutritional aspect is somewhat difficult to document since most PC cases with metastases are not nutritionally deficient by clinical parameters, such as body weight and measurement of postmortem subcutaneous fat layer thickness. In the control group studied in this reported, patients with advanced colon adenocarcinoma and lung carcinoma displayed no evidence of statistically significant reduction of testicular Leydig cells density as compared with compatible age group. Furthermore, the possibility that the PC with 
metastatic potential may express factor(s) that is suppressing either the function or the release of luteinizing hormone in vivo may also need to be studied.

\section{References}

[1] A. Jost, Problems of fetal endocrinology: the gonadal and hypophyseal hormones, Recent Progr. Horm. Res. 8 (1953), 379418.

[2] P.K. Siiteri and J.D. Wilson, Testosterone formation and metabolism during male sexual differentiation in human embryo, J. Clin. Endocrinol. Metab. 38 (1974), 113-125.

[3] J.D. Wilson, Recent studies on the mechanism of action of testosterone, N. Engl. J. Med. 287 (1972), 1284-1291.

[4] J.L. Goldstein and J.D. Wilson, Hereditary disorders of sexual development in man. Birth defects, in: Proceedings of the 4th International Conference (Vienna) (International Congress Series No. 310), A.G. Motulsky and W. Lentz, eds, Excerpta Medica, Amsterdam, 1974, pp. 165-173.

[5] E.E. Baulieu, I. Lansinitzki and P. Robel, Metabolism of testosterone and action of metabolites on prostate glands grown in organ culture, Nature (London) 219 (1968), 1155-1156.

[6] R.M. Nesbit and W.C. Baum, Endocrine control of prostatic carcinoma, JAMA 143 (1950), 1317-1320.

[7] J.A. Gustafassor, P. Ekman, M. Snochowski, A. Zetterberg, A. Pousette and B. Hogberg, Correlation between clinical response to hormonal therapy and steroid receptor content in prostatic carcer, Cancer Res. 38 (1978), 4345-4348.

[8] C. Huggins and C.V. Hodges, Studies on prostate cancer. 1. The effects of castration, of estrogen and of androgen injection serum phosphatases in metastatic carcinoma of prostate, Cancer Res. 1 (1941), 293-297.

[9] C.E. Blackard, D.F. Byer and W.P. Jordan, Orchiectomy for advanced prostatic carcinoma, Urology 1 (1973), 553-562.

[10] W.V. Scott, M. Menon and P.C. Walsh, Hormonal therapy of prostate cancer, Cancer 45 (1980), 1929-1926.

[11] S.R. Ahmed, P.J.C. Brouman, S.M. Shalet, A. Howell, N.J. Blacklock and D. Rickards, Treatment of advanced prostatic cancer with LHRH analogue ICI 118630: clinical response and hormonal mechanisms, Lancet 2 (1983), 415-419.

[12] G. Tolis, D. Ackman and A. Stellos, Tumour growth inhibition in patients with prostatic carcinoma treated with luteinising hormone-releasing hormone agonists, Proc. Natl. Acad. Sci. (USA) 79 (1982), 1658-1662.
[13] M.L. Dufau, Endocrine regulation and communicating functions of the Leydig cell, Ann. Rev. Physiol. 50 (1988), 483-508.

[14] A.H. Payne and G.L. Youngblood, Regulation of expression of steroidogenic enzymes in Leydig cells, Biol. Reproduction 52 (1995), 217-225.

[15] J. Geller, J. Albert, D. Vega, D. Loza and W. Stoeltzing, Dihydrotestosterone concentration in prostate cancer tissue as a predictor of tumor differentiation and hormonal dependency, Cancer Res. 38 (1978), 4349-4352.

[16] W.B. Neaves, L. Johnson, J.C. Porter, C.R. Parker Jr and C.S. Petty, Leydig cell number, daily sperm production, and serum gonadotropin levels in aging men, J. Clin. Endocrinol. Metab. 55 (1984), 756-763.

[17] H.F. English, N. Kyprianou and J.T. Isaacs, Relationship between DNA fragmentation and apoptosis in the programmed cell death in the rat prostate following castration, Prostate $\mathbf{1 5}$ (1989), 233-250.

[18] N. Kyprianou, H.F. English and J.T. Isaacs, Programmed cell death during regression of PC-82 human prostate cancer following androgen ablation, Cancer Res. 50 (1990), 3748-3753.

[19] O.A. Armas, A.G. Aprikian, J. Melamed, C. Cordon-Cardo, D.W. Cohen, R. Erlandson, W.R. Fair and V.E. Reuter, Clinical and pathological effects of neoadjuvant total androgen ablation therapy on clinically localized prostatic adenocarcinoma, Am. J. Surg. Pathol. 18 (1994), 979-991.

[20] L. Vailancourt, B. Tetu, Y. Frader, A. Dupont, J. Gomez, L. Cusan, R. Suburu, P. Diamond, B. Candas and F. Labrie, Effects of neoadjuvant endocrine therapy (combine androgen blockade) on normal prostate and prostatic adenocarcinoma) a randomized study, Am. J. Surg. Pathol. 20 (1996), 86-93.

[21] Y. Umekita, R.A. Hippakka, J.M. Kokontis and S.T. Liao, Human prostate tumor growth in athymic mice: inhibition by androgens and stimulation by finasteride, Proc. Natl. Acad. Sci. (USA) 93 (1996), 11 302-11 807.

[22] K. Peach, P. Webb, G.G.J.M. Uiper, S. Nilsson, J.-A. Gustafsson, P. Kushner and T.S. Scanlan, Differential ligand activation of estrogen receptors ER and ER at AP1 sites, Science (Washington) 277 (1997), 1508-1510.

[23] G.G.J.M. Kuiper, E. Enmark, M. Pelto-Huikko, S. Bilsson and J.-A. Gustafsson, Cloning of a novel estrogen receptor expressed in rat prostate and ovary, Proc. Natl. Acad. Sci. (USA) 93 (1996), 5927-5930. 


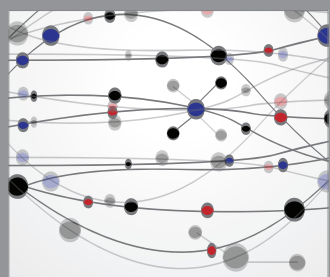

The Scientific World Journal
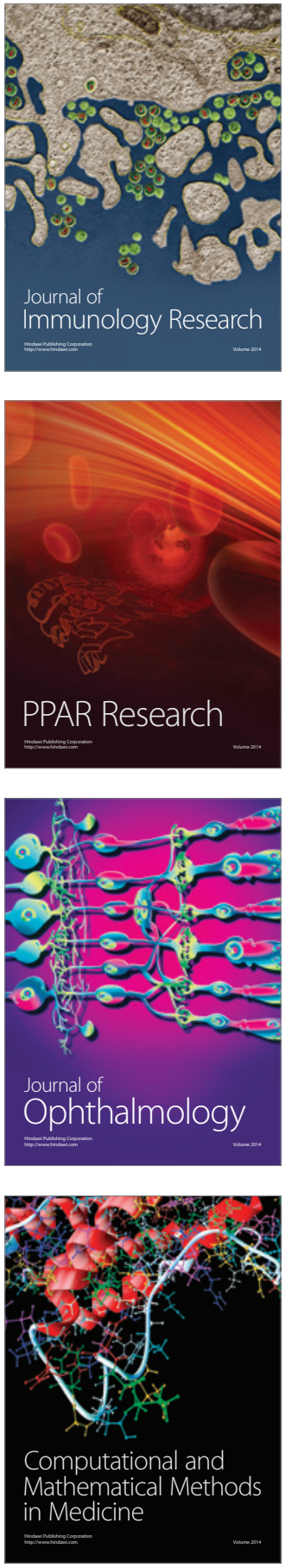

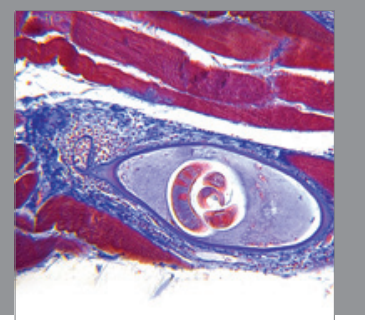

Gastroenterology

Research and Practice
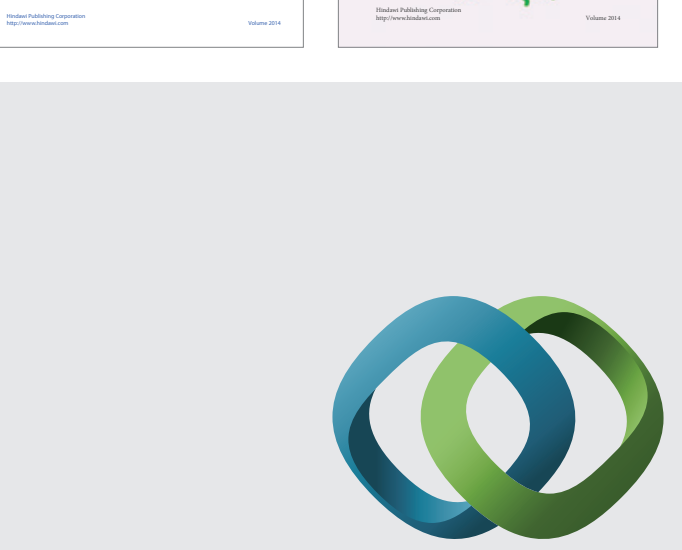

\section{Hindawi}

Submit your manuscripts at

http://www.hindawi.com
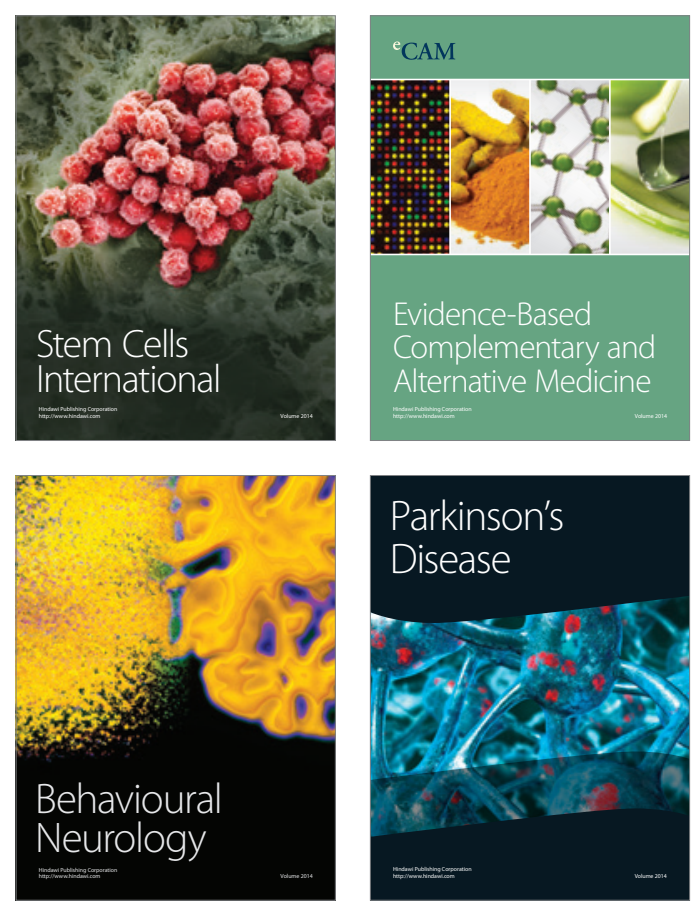

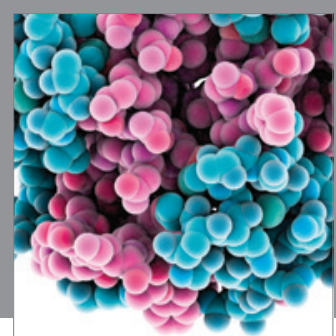

Journal of
Diabetes Research

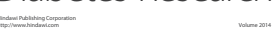

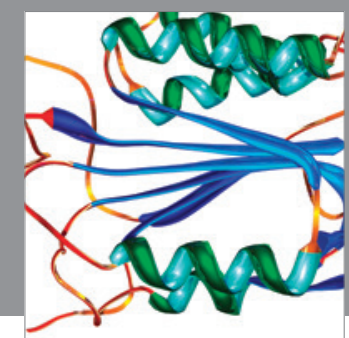

Disease Markers
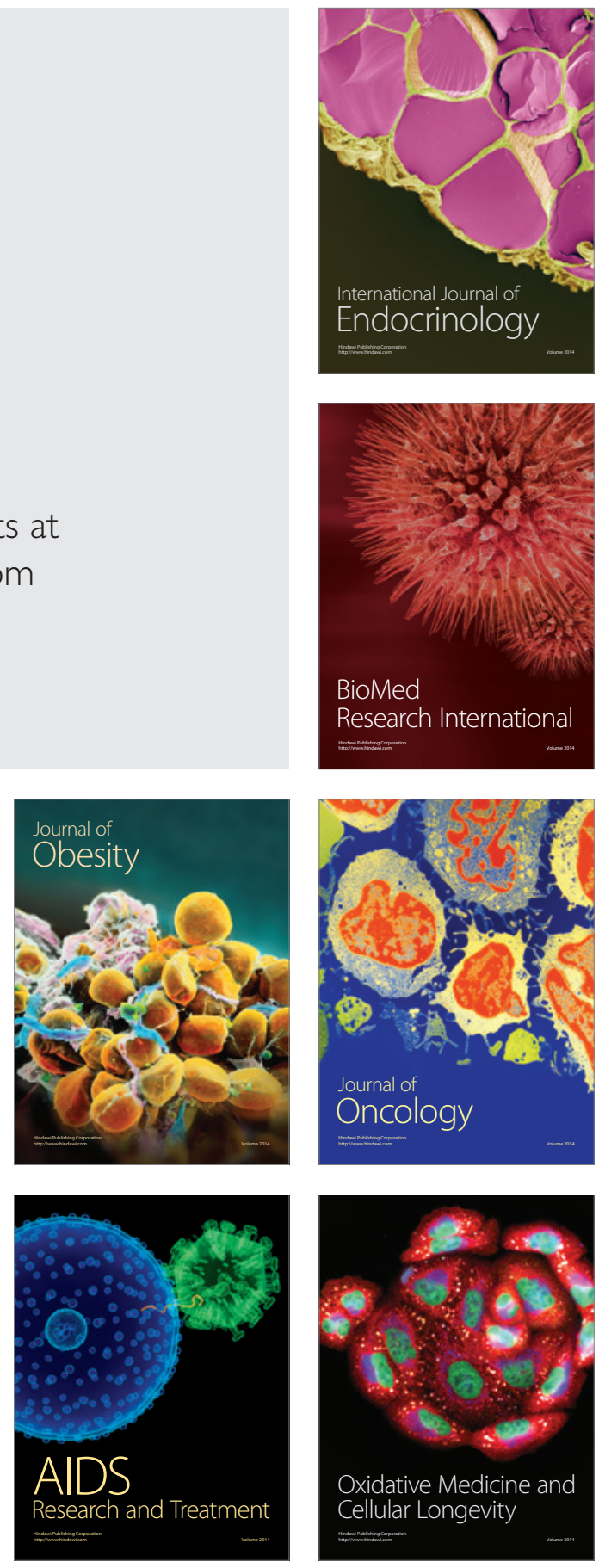